\title{
Need of Clinical Studies on the Efficacy of Nutraceuticals for Treating Brain Disorders
}

\author{
Muhammad Atif Raza Cheema ${ }^{1,2 *}$, Khalid Mahmood ${ }^{2}$, Darakhshan J Haleem ${ }^{2}$ and Rafeeq Alam Khan ${ }^{1}$ \\ ${ }^{1}$ Department of Pharmacology, Faculty of Pharmacy and Pharmaceutical Sciences, University of Karachi, Pakistan \\ ${ }^{2}$ Neuroscience Research Laboratory, Dr. Panjwani Center for Molecular Medicine and Drug Research, International Center for Chemical and Biological \\ Sciences, University of Karachi, Pakistan
}

Submission: December 11, 2017; Published: January 30, 2018

*Corresponding author: Muhammad Atif Raza Cheema, Neuroscience Research Laboratory (P-102), Dr. Panjwani Center for Molecular Medicine and Drug Research (PCMD), International Center for Chemical and Biological Science (ICCBS), University of Karachi, Karachi-75270, Pakistan. Tel: +92-21-99261681; Email: atifpharmacist3@iccs.edu

\section{Nutraceuticals to Prevent Brain Disorders}

In recent years, interest in the use of nutraceuticals has risen substantially, largely because of their safety, adequate efficacy, and potency [1]. Nutraceuticals is a broad term that describes products, which other than nutrition are also used as medicine. The 'Nutritional Psychiatry' is a new field of research focused on the role of diet and nutrition in mental health [2].

Good nutrition and healthy lifestyles are important not only to prevent mental disorders but equally during treatment of brain disorder to improve patient's response to treatment. Most brain disorders can be prevented by adopting healthy dietary habits and lifestyle modification (i.e. physical activity, exercise, meditation, diet, and restriction of caffeine, alcohol, and nicotine $[2,3]$. Amongst the 'nutraceuticals and functional foods' recommended for the prevention of mental illnesses include, but are not limited to, nutrient-dense foods (vegetables, fruits, and fish), Mediterranean diet, Olea europaea, and Nigella sativa [4]. A traditional Mediterranean diet, for instance, appears to have prophylactic benefits against anxiety, depression, and dementia [5]. Mediterranean diet includes higher intakes of fruits and vegetables, cereals with limited processing, fiber, fish, seafood, and only modest amounts of dairy and lean meats. Specific items within traditional dietary patterns (soy foods, honey, turmeric, blueberries, and pomegranate) have been individually associated with protection against depression and, experimentally, these components have also demonstrated antidepressant properties. The isolated polyphenols and different phytochemicals within these foods have likewise been reported to provide anti depressive properties in experimental models. In addition, specific nutrients, for example, magnesium, zinc, vitamin C, folic acid, and vitamin B12, have additionally been associated with resiliency against depression or improvement in depressive symptoms [6].
It has been reported that Olea europaea (olive) oil, a major component of the Mediterranean diet also has neuro protective effects [1]. Nigella sativa, commonly known as Black cumin or Black seed, has been traditionally utilized for culinary and therapeutic purposes [1]. Several studies showed that Nigella sativa has neuro-protective effects [7] as well as protects against memory impairments [8]. Thymoquinone, the main active component of Nigella sativa have also shown neuro protective effects [9].

Nigella sativa and Oleaeuro Pae produce their beneficial effects through the modulation of neurotransmitters in the brain. These neurotransmitters in turn alleviate depression, anxiety, and help in memory enhancement [1].0n the other hand, diet, physical activity, exercise and smoking may influence mental health through various distinctive pathways, including via alteration of neurotrophins critical to depression [10]. Thus nutraceuticals and functional foods have the potential to stimulate the central nervous system and protect the brain against various damages [8]. The philosophy behind the use of nutraceuticals is to focus on prevention of disease, as said by Hippocrates "let food be your medicine" [11].

\section{Nutraceuticals for the Treatment of Brain Disorders}

Healthy dietary habits and good nutrition can help patients deal with the effects of mental disorders and their treatment. Most prescription drugs, such as antidepressants, antipsychotics, anxiolytics, and psychostimulants produce side effects [12]. This usually causes noncompliance in patients. An alternate for psychiatrists to overcome this noncompliance is to utilize safe alternative or complementary nutritional therapies [13]. Promoting an increased consumption of nutrient-dense foods may be a helpful strategy in the prevention and treatment of mental disorders $[10,14]$. 
Moreover, taking healthy nutrition such as supplements containing amino acids have also found to reduce symptoms of depression and mental illnesses. Dietary supplements containing tyrosine and/or phenylalanine cause alertness and arousal. Omega-3-fatty acids in fish oil have been found to elicit antidepressant effect and are also used as an adjunctive therapy for mood disorders. Fish oil supplementation may also offer a safe strategy for attenuating post-traumatic stress disorder [15]. Folate and vitamin B12 can also be used to decrease the symptoms of depression. These foods facilitate the production of neurotransmitters in the brain. The neurotransmitters in turn alleviate depression and other mental illnesses [13].

It has been reported that Olea europaea oil also has anxiolytic, antidepressant, and memory enhancing effects $[1,16]$. It has been shown that Nigella sativa has anxiolytic [17], antidepressant [18], as well as nootropic effects [1]. Thymoquinone have also shown improvement of stressinduced impairment of memory [19]. Nigella sativa might be a potential source for developing new drugs for treating anxiety and stabilizing mood and improving cognition in adolescents $[1,20]$.

On the other hand, a 'processed food' pattern (sweetened desserts, fried food, processed meat, and refined carbohydrates) is positively related to the risk for later depression [4]. Unhealthy maternal and early postnatal dietary patterns (processed and refined foods, high-sugar beverages, and highsodium snacks) elevate the risk of behavioral and emotional problems in children [21]. The increasing availability of highly palatable diet and sedentary life style is of great concern in the epidemic of obesity and depression worldwide [22-23].

\section{Conclusion}

The emerging field of Nutritional Psychiatry offers much promise for identifying and addressing the large disease burden associated with mental disorders that account for the leading disability burden globally. Evidence suggests that majority of nutraceuticals possess multiple pharmacological properties to help treat brain disorders. However, clinical studies on the use of these nutraceutical compounds in preventing and treating brain disorders are lacking. Evidencebased research on nutraceuticals being marketed is needed to develop effective strategies for treatment of mental disorders.

\section{References}

1. Cheema MAR, Nawaz S, Gul S, Salman T, Naqvi S (2016) Neurochemical and behavioral effects of Nigella sativa and Olea europaea oil in rats. Nutr Neurosci 1-10.

2. Jacka FN (2017) Nutritional Psychiatry: Where to Next? EBioMedicine 17: $24-29$

3. Sarris J, Moylan S, Camfield DA, Pase MP, Mischoulon D, et al. (2012) Complementary Medicine, Exercise, Meditation, Diet, and Lifestyle Modification for Anxiety Disorders: A Review of Current Evidence. Evidence-Based Complement. Altern Med p. 1-20.

4. Akbaraly TN, Brunner EJ, Ferrie JE, Marmot MG, Kivimaki M, et al.
(2009) Dietary pattern and depressive symptoms in middle age. Br J Psychiatry 195(5): 408-413.

5. Himmerich H, Erbguth F (2014) Ernährung and Nahrungsergänzungsmittel bei psychiatrischen Erkrankungen. Nervenarzt 85(12): 1512-1520.

6. Selhub EM, Logan AC, Bested AC (2014) Fermented foods, microbiota, and mental health: ancient practice meets nutritional psychiatry. J Physiol Anthropol 33: 2.

7. Kanter M (2008) Nigella sativa and derived thymoquinone prevents hippocampal neurode generation after chronic toluene exposure in rats. Neurochem Res 33(3): 579-588.

8. Azzubaidi MS, Saxena AK, Talib NA, Ahmed QU, Dogarai BB (2012) Protective effect of treatment with black cumin oil on spatial cognitive functions of rats that suffered global cerebrovascular hypoperfusion. Acta Neurobiol Exp (Wars) 72(2): 154-165.

9. Darakhshan S, Bidmeshki PA, Hosseinzadeh CA, Sisakhtnezhad S (2015) Thymoquinone and its therapeutic potentials. Pharmacol Res 95-96: 138-158.

10. Jacka FN, Mykletun A, Berk M (2012) Moving towards a population health approach to the primary prevention of common mental disorders. BMC Med 10: 149.

11. Oszkiel H, Wilczak J, Jank M (2014) Biologically active substancesenriched diet regulates gonadotrope cell activation pathway in liver of adult and old rats. Genes Nutr 9(5): 427.

12. Thompson A, Silverman B, Dzeng L, Treisman G (2006) Psychotropic Medications and HIV Clin Infect Dis 42: 1305-1310.

13. Sathyanarayana Rao T, Asha M, Ramesh B, Jagannatha Rao K (2008) Understanding nutrition, depression and mental illnesses. Indian J Psychiatry 50(2): 77-82.

14. McMartin SE, Jacka FN, Colman I (2013) The association between fruit and vegetable consumption and mental health disorders: evidence from five waves of a national survey of Canadians. Prev Med (Baltim) 56(3-4): 225-230.

15. Nishi D, Koido Y, Nakaya N, Sone T, Noguchi H, et al. (2012) Fish Oil for Attenuating Posttraumatic Stress Symptoms among Rescue Workers after the Great East Japan Earthquake: A Randomized Controlled Trial. Psychother Psychosom 81: 315-317.

16. Perveen T, Hashmi BM, Haider S, Tabassum S, Saleem S, et al. (2013) Role of monoaminergic system in the etiology of olive oil induced antidepressant and anxiolytic effects in rats. ISRN Pharmacol.

17. Perveen T, Haider S, Kanwal S, Haleem DJ (2009) Repeated administration of Nigella sativa decreases 5-HT turnover and produces anxiolytic effects in rats. Pak J Pharm Sci 22(2): 139-144.

18. Perveen T, Haider S, Zuberi NA, Saleem S, Sadaf S (2014) Increased 5-HT Levels Following Repeated Administration of Nigella sativa L. (Black Seed) Oil Produce Antidepressant Effects in Rats. Sci Pharm 82(1): 161-170.

19. Cheema MAR, Haleem DJ (2015) Attenuation of Stress-Induced Learning and Memory Impairment by Thymoquinone Administration in Rat Models., 51st Annual Medical Symposium, Jinnah Postgraduate Medical Centre, Karachi-75270, Pakistan.

20. Bin Sayeed MS, Shams T, Fahim HS, Rahman MR, Mostofa A (2014) Nigella sativa L. seeds modulate mood, anxiety and cognition in healthy adolescent males. J Ethnopharmacol 152(1): 156-162.

21. Jacka FN, Ystrom E, Brantsaeter AL, Karevold E, Roth C (2013) Maternal and early postnatal nutrition and mental health of offspring by age 5 years: a prospective cohort study. J Am Acad Child Adolesc Psychiatry 52(10): 1038-1047.

22. Mahmood K, Haleem DJ (2017) Linking Leptin Resistance with Obesity and Depression. In: $6^{\text {th }}$ International Symposium-Cum-Training Course 
This work is licensed under Creative Commons Attribution 4.0 License

DOI: $10.19080 /$ NFSIJ.2018.04.555650

\section{Your next submission with Juniper Publishers} will reach you the below assets

- Quality Editorial service

- Swift Peer Review

- Reprints availability

- E-prints Service

- Manuscript Podcast for convenient understanding

- Global attainment for your research

- Manuscript accessibility in different formats

( Pdf, E-pub, Full Text, Audio)

- Unceasing customer service

Track the below URL for one-step submission https://juniperpublishers.com/online-submission.php 